\title{
Why University Teacher Preparation Programs Should Provide A New Set Of Personal Constructions Of Mathematics Through Math Content Courses For Elementary Teachers
}

Patricia A. Sellers, (E-mail: psellers@depauw.edu), DePauw University

\begin{abstract}
Teacher preparation programs are in danger of seriously under-preparing elementary teachers to teach mathematics for understanding if they wait to provide students with evidence of effective mathematics teaching methods in the mathematics methods courses. With strong traditional beliefs about how mathematics ought to be taught and their determination to be able to explain mathematics to elementary children, the methods course is much too late to change preservice teachers' perceptions of mathematics or how to teach it. If we want to change the way they teach mathematics, we must do it in their mathematics content courses. In the content courses, we have a chance to provide them with positive and successful personal mathematics constructions. Only when they learn to become active problem-solvers, can they teach others the importance of interactive problem solving as a means of truly understanding mathematics. It is only through their own experience with mathematics that they can come to appreciate the value of a studentcentered environment for learning and to appreciate how a teacher's desire for control can stifle true learning.
\end{abstract}

\section{Introduction and Rationale}

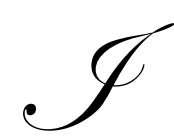

f we want to change the way teachers teach mathematics, the math methods course is too late and holds little hope. Prospective teachers hold beliefs about mathematics based on their own experiences as learners of mathematics. There is a growing body of research documenting the strength of teacher beliefs and the part they play in the methods teachers choose to use in the classroom (Golafshani, 2002; Fosnot \& Dolk, 2001; Wiersma \& Weinstein, 2001; Sellers \& Ahern, 2000; Burrill, 1998; Hiebert et al, 1997; Yackel \& Cobb, 1996).

According to Golafshani (2002), "A person's understanding of the nature of mathematics predicates that person's view of how teaching should take place in the classroom" (p.2). In Hiebert et al (1997), the authors report that

"students form their perceptions of what a subject is all about from the kinds of tasks they do. If they are asked in history class only to memorize the names, dates, and locations of historical events, they will think that history is about remembering facts from the past. If students are asked in mathematics class only to practice prescribed procedures by completing sets of exercises, they will think that mathematics is about following directions to move symbols around as quickly as possible. If we want students to think that mathematics means solving problems, they will need to spend most of their time solving problems. Students' perceptions of the subject are built from the kind of work they do" (p. 17). 
As a consequence of their beliefs, many students believe that good math teachers must be able to explain how to do math problems clearly and that through those explanations children will learn math. Current research on mathematics teaching and learning now tells us that children do not truly understand mathematics when they are simply told how to do it and asked to memorize the procedures for doing so (Kamii \& Dominick, 1998).

If we are to produce teachers of mathematics who will change that perception of the nature of mathematics for their students, then we need to work on the belief systems of the prospective teachers. The newer reform methods based on the constructivist work of Jean Piaget have proven to be more effective ways of teaching mathematics for understanding, but prospective teachers find those methods difficult to believe based on their past experiences in learning mathematics (Wiersma \& Weinstein, 2001).

Wiersma \& Weinstein (2001), report on a variety of models of mathematical sophistication and find research to substantiate the claim that most preservice and in-service elementary teachers are at a relatively low level of mathematical sophistication. Furthermore, they report that those at low levels of sophistication have difficulty understanding reform methods of teaching mathematics, and are least likely to be prepared to grasp the actions necessary to become effective mathematics teachers.

Most of the research world would like to believe that the teaching of mathematics is changing in schools. However, Sellers \& Ahern (2000) report after twelve years of methods classes that initial math methods class questionnaires still find that over $90 \%$ of pre-service teachers still continue to believe that they need to be able to explain mathematical procedures to their students. They come from traditional mathematics backgrounds where mathematics was explained to them. They also report on the initial class questionnaire that they learn mathematics best when it is thoroughly explained to them and that they expect to be shown ways to "clearly explain" mathematics to children.

If we wait until the math methods course to introduce research on the newer and more effective methods of teaching mathematics, previous arguments show that students' personal beliefs almost always override even the logic of the research. As a result, they disbelieve the research and find it too incredible to believe that it will work with their students. We need to look at courses prior to the math methods courses to see where we might be able to change the students' perceptions of mathematics itself if we hope to override the powerful mathematical beliefs of preservice teachers. It is in the math content courses where we can provide prospective teachers with a new set of personal constructions of mathematics, hopefully changing their perception of the nature of mathematics.

\section{The Goal of the Paper}

The goal of this paper is to report on the planning, implementation and outcome of a math content course for elementary teachers that provides them with opportunities to build a new perception of the nature of mathematics. This can only be done by providing them with the kind of experiences that will change their personal constructions of mathematics. The two primary methods utilized in the math content courses are problem-centered learning and inductive reasoning strategies. Students build their own constructions of mathematics by doing mathematics, by debating the merits of a variety of methods, and by class consensus of ways to record, model, and do mathematics.

According to Kubinova (1999), there have been wide discussions among mathematics educators and researchers about the kind of changes to undergraduate teacher preparation programs that would be necessary to affect a change in the quality of teachers. Those discussions suggest that there must be changes in the process and the climate of undergraduate teacher preparation. Kubinova reports that it is "much simpler to teach students (including future teachers) skills and knowledge without understanding than it is to teach them with understanding, the ability to use their knowledge and to be independent and self-confident" (p.1). She also suggests that we fail to pose the hard question of how we will go about developing teachers who can meet those criteria.

In 2001, the Conference Board of the Mathematical Sciences (CBMS) put together a Steering Committee of ten and a writing committee of four, all professionals in mathematics education, to produce a "report designed to 
be a resource for mathematics faculty and other parties involved in the education of mathematics teachers" (p. ix). According to their preface, they also include current research on curriculum and policy issues, attempt to keep their advice aligned with the National Council of Teachers of Mathematics Principles and Standards for School Mathematics, focus on preservice education, and suggest ways to improve mathematics education. They include recommendations for elementary teacher preparation and a chapter on the preparation of elementary teachers.

The CBMS (2001) first makes the argument that "it is during the elementary years that young children begin to lay down those habits of reasoning upon which later achievement in mathematics will crucially depend" (p. 11). They then proceed to make similar arguments made previously in this paper, going so far as to say that " many teachers were convinced by their own schooling that mathematics is a succession of disparate facts, definitions, and computational procedures to be memorized piecemeal. As a consequence they are ill-equipped to offer a different more thoughtful kind of mathematics instruction to their students" (p. 17). They claim that we are caught in a vicious cycle: poor K-12 mathematics instruction produces ill-prepared college students, and undergraduate education often does little to correct the problem" (p. 55). They also point out that universities have still done very little to change this situation. In fact, they report that universities don't even require enough mathematics coursework to change the fates of elementary teachers. Perhaps, more importantly, they point out that if universities did in fact provide enough mathematics coursework for elementary teachers, that it would probably not be a solution. They fear that students would get more of the same ill preparation in undergraduate math courses that they got in their K-12 math preparation.

They do however, say that:

"it is possible to break this cycle. College students with weak mathematics backgrounds can rekindle their own powers of mathematical thought. In fact, elementary teachers do so: with classroom experiences in which their ideas for solving problems are elicited and taken seriously, their sound reasoning affirmed, and their missteps challenged in ways that help them make sense of their errors. Teachers able to cultivate good problem solving skills among their students must, themselves, be problem-solvers, aware that confusion and frustration are not signals to stop thinking, confident that with persistence they can work through to the satisfactions of new insight. They will have learned to notice patterns and think about whether and why these hold, posing their own questions and knowing what sorts of answers make sense. Developing these new mathematical habits means learning how to continue learning" (p. 17).

Just as Hiebert et al (1997) suggest in Making Sense, the CBMS (2001) committee suggests that teachers, while they are students of mathematics, must learn to make sense of mathematics. They must move themselves to the kind of higher order thinking, generalizations, and rigor that was probably not present in their own elementary educations.

The CBMS (2001) suggestions all point to the undergraduate mathematics coursework because "they, just like the children they will someday teach, must have classroom experiences in which they become reasoners, conjecturers, and problem-solvers" (p. 56). These suggestions cannot take place in a methods course. They must take place in a new kind of mathematics content course, where we break this cycle of ill preparation. It is clear that teachers can no longer afford to be ill prepared to teach mathematics (even elementary), by means of the traditional mathematics lecture courses. They must become problem-solvers, and one cannot become a problem-solver in a passive learning environment.

For the first time in twelve years of teaching mathematics methods courses for elementary teachers, the author was given the opportunity to teach the mathematics content courses for the elementary education majors. After reading the CBMS (2001) report and considering the relatively low success rate of changing the belief systems of preservice elementary teachers in the methods courses, it was decided that a problem-centered mathematics course was in order.

Having successfully implemented the inductive teaching strategies coined by James Cangelosi (2003) and problem-centered sessions as a Comprehensive School Reform Demonstration (CSRD) Act consultant for 5 years in 
a Title I school in a large Midwest city, it was decided to use a combination of those two strategies for the mathematics content course. The success of those strategies as a consultant was based on teacher and student attitudes towards mathematics, higher general achievement as measured by teachers and higher achievement as measured by the state standardized mathematics test.

There are many traditionally used textbooks for mathematics courses for elementary teachers, but most do not even attempt to supply the kinds of experiences suggested by the CBMS (2001) report. Most of the texts traditionally introduce content by explaining it, giving numerous worked examples and following that with numerous exercises where students can practice their newly acquired skills. The methods students are exposed to the Hiebert et al (1997) Making Sense text, and the Fosnot \& Dolk (2002) Young Mathematicians at Work series. All four of these books expose methods students to five internationally known successful elementary mathematics programs and the theories underlying their success. They are marginally successful in persuading preservice teachers that students do not learn mathematics through a "show, tell and demonstrate" method, a.k.a. the ill preparation of their own mathematics educations.

Education students with a vision and desire to really affect the learning of their own students in such a way that they want to learn mathematics can become persuaded of the validity of the methods used in those books. They can even be persuaded to try some of those methods in a brief internship prior to their student teaching. However, the majority of the methods students still adhere to the traditional "show, tell, and demonstrate" methods as evidenced in observations of their internship teaching episodes. In fact, the good mathematics students are usually the hardest students to convince that changes in teaching elementary mathematics must happen if students are to truly understand mathematics. After all, they got "A's" by having math explained to them, by memorizing procedures, and by practicing the application of topics many times. The marginally successful or unsuccessful mathematics students are the ones who more likely see the need for change, because they know that they did not truly understand or like mathematics. However, they are not the ones who have the mathematical prowess to plan the best mathematical plans designed to ask their students to think and reason. They are so afraid that they will be asked questions they cannot answer, that they are literally afraid to try some very effective strategies suggested in their methods books. The effective strategies, demand that the elementary students do the thinking and reasoning, that the teacher guide the mathematical exploration, ask good probing questions, and detect germs of good mathematical thinking. The effective strategies also suggest that the teacher trust the logic and structure of mathematics to guide the majority of the children's thinking and dare to suggest that mistakes are sites for learning (Hiebert et at, 1997). Poor mathematical students have difficulty trusting their own ability to plan these kinds of lessons or to carry them out with actual students.

\section{Mathematics for Elementary Teachers I - Mathematics Content Course I}

After surveying a variety of mathematics professors who taught math content courses for elementary teachers, the author was able to find a suitable textbook that met all of the CBMS (2001) criteria. The textbook also met the author's own criteria of finding tasks permitting a problem solving perspective or that could be introduced through an inductive reasoning strategy. The textbook chosen was Mathematics for Elementary Teachers via Problem Solving (Masingila, Lester, \& Raymond, 2002). Students were required to purchase the Student Activity Manual, which contained very little topic or resource information. The Student Resource Manual was optional. As it turned out, most students bought the optional manual, but eventually came to rely on the consensus of the class and to only use the Resource Manual as a way to do a little extra reading on topics that were leaving them with questions. The Resource Manual had minimal explanatory material, yet gave additional web sites, or sources that students could check out if so motivated.

Ground rules had to be set for the course. Those ground rules involved the students as well as the professor. If this was to be an interactive problem solving course, the ground rules had to be spelled out and the professor had to be cognizant of the teaching strategies and their students' thinking processes at all times. 


\section{Ground Rules for Students}

- $\quad$ Students will be given a task, which they will work on in groups of 3 or 4 .

- $\quad$ Students will be responsible for their own learning. Nothing will be directly explained to them by the professor, only by their peers.

- Students will not be allowed to ask the professor for any guidance during the initial phase of problem solving.

- $\quad$ Students in groups will all be responsible for explaining the methods the group used to solve the problem.

- $\quad$ The professor will be allowed to ask questions of the groups as they work on the problems or tasks to verify that all students are taking responsibility for solving the problem and/or to determine each student's role in the process.

- $\quad$ Students will be volunteering to demonstrate how they arrived at their answers, being sure to give credit to the group for group consensus thinking.

- $\quad$ All students will make a concerted effort to understand the explanations of their peers.

- Students will be responsible for asking peers to clarify their thinking if they do not feel they can follow or understand the explanation.

- $\quad$ Students will keep a pocket notebook that will be collected at three designated times throughout the semester. The notebook will contain all of their own work on group problems, some individually assigned problems, and assigned journal writings or additional explanations of their use of strategies for each of the group problems.

- The exams will consist of two parts. The first part will be 1 hour of individual problem solving followed by 50 minutes for a group problem.

- $\quad$ The exam score will be the mean of the individual and the group portion of the exam.

\section{Ground Rules for the Professor}

- $\quad$ The professor will not be allowed to explain anything beyond the assignment of the task.

- The professor's primary task will be to follow the thinking processes and explanations of their students and/or groups and to direct the group discussions.

- $\quad$ Even, if students asked for clarification of the essence of the problem, the professor will turn their questions into further questions.

- If the professor discerns that a group has ignored an aspect of the problem, they will be allowed to ask questions that might suggest an ignored aspect of the problem.

- $\quad$ The professor's usual response to questions asking for verification of right or wrong answers will be to indicate that the thinking certainly was interesting. This is to assure that students will learn that the professor will not be considered the sole authority or a walking encyclopedia of knowledge or truth.

- $\quad$ The professor will encourage the groups to debate each other if they disagree or if they misunderstand a groups' explanation of their thinking process.

\section{Goals for problem solving, whole class discussion and/or inductive reasoning}

- $\quad$ The professor will look for groups to call on that might be recording their thought processes in unique ways, so that other groups and/or students will eventually come to realize the importance of recording their thought processes.

- The professor will look for groups that are learning to systematically record their "trials" if using a "trial and error" process.

- The professor will ask the students to identify their method or strategy, so that students in time will come to think of strategies by descriptions or names.

- $\quad$ The professor will encourage students to justify their thinking, by examples or non-examples, and will be prepared to ask the "why" questions if the remaining students or groups do not ask "why" the student did what they did or knew how or when to do what they did. 
- $\quad$ The professor will challenge students to go beyond the initial problem, so will prepare additional challenge questions if the text does not supply them.

- $\quad$ The professor will encourage the students to see the importance of multiple representations of their work, so will ask the students to do essentially three things for each problem: 1) to record all their work, 2) to explain in words their use of strategies and how they solved the problem, and 3) to draw pictures of any manipulatives used as a visual to solve the problem.

- The professor will encourage the students to see the important mathematics involved in the problem. If students are not using correct mathematical terminology or are failing to mention the major mathematical ideas involved, the professor will be prepared to ask questions to draw out the mathematical concepts involved.

\section{Sample problematic tasks}

I. The Game of Poison: Form two teams in your group. One team will play against the other team. Your instructor will give you 10 tiles. Place the 10 tiles between the two teams, and follow these rules:

- $\quad$ Decide which team should go first.

- When it is your team's turn, you must take one or two tiles from the table.

- $\quad$ Alternate turns until there are no tiles remaining on the table.

- $\quad$ The team who takes the last tile, the "poison" tile, is the loser.

- $\quad$ Play several games of Poison and try to determine a good strategy for winning.

- What if you start a game with 9 tiles, with 11 tiles, with 12 tiles?

- $\quad$ Can you determine a strategy for winning Poison no matter how many tiles you have at the start of the game?

- What makes a strategy a good strategy?

- What strategies did you use to find a way to win Poison no matter how many tiles you started with?

II. The Xmania Unit by Schifter and Fosnot (1993) - to satisfy the CBMS (2001) section of the importance of place value - and that place value involves significant conceptual issues for young children and for teachers and the unit that most students claimed was the best part of the course.

- $\quad$ Students are told that they are to devise a number system using only the symbols A,B,C,D, and 0 .

- $\quad$ Students came up with systems that paralleled the Egyptians and the ancient Greeks (the Roman Numeral System) and systems of their own.

- $\quad$ Then they were asked to learn to count in their system.

- $\quad$ They were asked to be sure their system had a unique representation for each number and that they could represent very large and very small numbers.

- The most important part of this section is the development of their own systems, their exploration of it, their encounter with its limitations, and their eventual understanding that a place value system is most efficient.

- $\quad$ Students are asked to learn to add, subtract, multiply, and divide in this system.

- $\quad$ Students are encouraged to use manipulatives representing their base 5 system.

- $\quad$ Students keep journal entries about how well they can "think" in Xmania, without converting back and forth to a base ten value to perform operations in Xmania.

- $\quad$ Students who claim to understand place value, struggle at some point, which may be different for different students, and come to understand the frustration that students go through trying to learn our base ten system for the first time and to count and perform operations within the place value system.

III. The Locker Problem - part of the Number Theory Chapter

- $\quad$ Students at an elementary school decided to try an experiment. When recess is over, each student will walk into the school one at a time. The first student will open all of the first 100 locker doors. The second 
student will close all of the doors with numbers that are multiples of two. The third student will change all of the locker doors with numbers that are multiples of three. (Change means closing locker doors that are open and opening lockers that are closed.) The fourth student will change the position of all locker doors with numbers that are multiples of four; the fifth students will change the position of the lockers that are multiples of five, and so on. After 100 students have entered the school, which locker doors will be open?

- This problem is indicative of how the problems came to look as we neared the end of the semester. The problems were more open-ended and the students were left to decide on strategies, to implement them, to record their implementation, to look for patterns, and to make generalizations or find solutions.

\section{The Process}

In the beginning the students were very tentative about working together, sharing ideas, trying ideas, making mistakes, and digging deeply into the essence of the problems. They were satisfied that they had solved the problem if they found one answer and they were satisfied with their answers without thinking critically about how realistic and reasonable they might be. The class had 15 students and 4 groups of either 4 or 3 students. The groups were changed for each new problem, so that by the end of the semester each student had worked with every other student at least twice. The first time the professor wanted to change the groups, she made it into a problem. Was there a way to change the groups to guarantee that no two people worked together again in the second group? This only worked once in a small class, and the professor didn't want to miss an opportunity to show the students that routine things that happen in a classroom can be turned into a problem. The students took on the challenge and two students figured out how this could be done. We acted out both of their methods, so they could "see" their successful thinking.

For example, the first two groups who volunteered to share their solutions to the Poison game had concluded that you just had to take the opposite number of tiles from the opponent to win the game. They also thought that they had found a pattern in that each time you had an even number of tiles you could win the game, and each time you had an odd number of tiles, you would lose the game. They had failed to record any of the moves they made each time they tried the game and relied on being able to reproduce the outcomes in front of the class exactly as they had done in their group. When the outcome didn't match their expectations, they said that they must have done something wrong and started over. They also never considered that the opponent would not have to take the number of tiles that they expected them to take if both sides followed the pattern of taking the opposite number of tiles (1 or 2) than the last play. One group had figured out the exact pattern and rule for winning the game and was anxious to show the class and prove the others wrong. The professor had asked them to only ask questions of the other groups or to volunteer to play as the opponent with the other groups to try to uncover the fallacies in the presenting groups' reasoning.

After several games showed that the first two groups conclusions only held up under certain conditions and were not generally true, a third group (whose reasoning was quite good, but not yet generalized) refused to share their thinking because they said they were confused. The professor asked the group who had correctly figured out the generalized solution to the game to share just the beginning of their work with the rest of the class. The purpose in doing this was to get the other groups to realize that they had failed to find a way to record what happened as they played the games. There were moans of disappointment and cries of joy as each of the groups began to uncover fallacies in their thinking or to find a way of recording that allowed them to see patterns they had failed to see before.

Finally the fourth group was asked to share their thinking about the problem. Interestingly enough they had written their conclusion using $3 n, 3 n-1$ and $3 n-2$. This was confusing to some of the students who thought they had it figured out as $3 n, 3 n+1$ and $3 n+2$, so there was confusion as to which generalized form made sense. As the groups presented their patterns and their solutions, it became clear that both sets of notations were logically correct, but that the solutions had to be carefully matched because $3 n-1$ and $3 n+1$ did not have the same outcome and therefore different solutions. When asked what lessons and strategies had helped them to solve the problem, the class had made some interesting discoveries. They learned that finding a way to record what they were doing was essential to finding patterns. They learned that starting small made more sense, than to start out with larger amounts of tiles - 
there were fewer details to keep track of when starting small. They learned to be open to more possibilities than just the ones they set before themselves. They learned to find ways to justify their thinking. They learned to be more open about sharing. They learned the value of group consensus. They learned the value of persistence. And, in the end, they learned that they were capable of solving problems and became a bit more confident in their abilities each time they had even small successes or contributions to the group or to the class.

The professor's most difficult task was not in following their thinking, although at times it took more than one explanation to get a clear picture of their thinking. The professor did however, have to learn to think outside of her own thinking and to be open to all suggestions, even if they seemed unrealistic at first. The most difficult part was not giving hints and not verifying answers as either correct or incorrect. The professor did occasionally have to paraphrase what she thought a group was trying to convey, when everyone else said they were confused.. Sometimes she was successful and sometimes she needed to step back and let other students try to make sense of their peer's explanations.

\section{The logic behind the task and/or the method}

Hilda Taba (in Joyce, Weil, and Calhoun, 2000) coined the term "teaching strategy" and identified a series of steps designed to develop inductive reasoning processes. While most of the tasks presented to the students could be classified as problematic tasks, it was the excitement of the inductive reasoning process that also kept the students motivated.

Students were presented with specifics and asked to logically come up with generalizations that would describe the specifics. I cannot locate one problem or task given to the students where they were given generalized rules and asked to deductively reason from the general to the specific. Once they had generalizations, they could supply additional specific cases to either fit the generalization or not. Inductive reasoning tasks are like asking students to play detective and to figure out how or why something could possibly happen. The students looked forward to the class, rarely missed and often stayed after to "throw" out a new idea. If we were in the middle of a problem solution or the groups did not have enough time to find something they wanted to share, we let one task or problem flow across two class times. We did not rush to closure. In fact, some of the students needed individual thinking time and the extension of the problem across two class times provided that individual thinking time. Little by little, I noticed that more of the students were taking advantage of thinking about their own solutions outside of class, because they would come to their groups excited to share their new findings.

Yackel and Cobb (1996) examine the sociomathematical norm, argumentation, and autonomy in the mathematics classroom. The professor sensed all along that her role could make this a successful endeavor or simply turn it into another experience of ill preparation by taking on a more traditional focus and simply telling the students too much, thus robbing them of their own thinking experience and mathematical construction. It is easy to work with children and pretend to not know where they are going with their thinking so they will continue to think. It is not as easy as one might think to give college students a first impression that you have no clue where they are headed and to give them free reign to their own thinking. One does, however, have to be constantly aware of where each line of thinking might be taking a student or the class. In that respect I would have to agree with Yackel and Cobb when they say that:

"The analysis of sociomathematical norms indicates that the teacher plays a central role in establishing the mathematical quality of the classroom environment and in establishing norms for mathematical aspects of students' activity. It further highlights the significance of the teacher's own personal mathematical beliefs and values and their own mathematical knowledge and understandings" (pg. 475).

The teacher's role is crucial to the amount and kind of thinking the students are asked or allowed to do.

Steffe and DeAmbrosio claim that there is a kind of teaching that can be called "constructivist teaching". They "emphasize that the design of the learning space includes three principal currencies of a mathematics teacher: the posing of situations, the encouragement of reflection, and interactive mathematical communication" (p. 156). 
They further state that "we pose situations that help students sustain their mathematical activity and develop confidence in their ability to do mathematics without the help of a teacher or more able peers" (p. 157). My students were asked to pose problem situations similar to tasks they were given and also to pose examples that could justify or disprove generalizations. Could this model of teaching be called "constructivist teaching"? It would take a closer look at specifics within the classroom to confirm or deny this. Constructivism has not been emphasized in this paper, except that it is the underlying philosophy in the mathematics methods course these students will be taking prior to student teaching. The textbooks, listed previously, were chosen with this end in mind. So to be able to model a method even close to "constructivist teaching" with these students in their math content courses should serve several purposes. It would give them a glimpse into the methods they will read about and be asked to try in the methods course. It will expose them to something very non-traditional and most likely unfamiliar to them, given the nature of most of their mathematical backgrounds. And, hopefully it will allow them to experience mathematics in a way that will cause them to re-think their old beliefs about the nature of mathematics and how they think it should be taught.

\section{Student Reflections about how this course was different than their other math courses and what they feel they learned}

So far, the only proof that this kind of mathematics course is reaching the goals set for it is a list of comments from students' final reflections about the course. These students will be exposed to a second mathematics content course utilizing the same text and with the same professor before they are ready for the math methods courses next year. Where will the real proof of success come from? It will come from observations of these students as they plan mathematics lessons and implement them first in an internship, then in their student teaching. Perhaps proof of success may even have to wait until these students are in their second or third year of real teaching, for only then are we able to look for evidence that parts of our teacher preparation program have been integrated into their own teaching choices, methods, and styles.

The following comments have been chosen as indications of the attainment of the course goals (Note: I am limited by space here because all students in the class made very positive comments):

Student \#1: This class has taught me so much about math. I don't even know where to begin. First of all, my main benefit from this class has been learning to think about math. Never before have I had to really think about a math problem. I've always been expected to simply follow an algorithm. I liked having to think about a problem first by myself before I could get any help from my professor. Having to explain a problem in words has also made me truly understand the problems as well. It is one thing to be able to solve a problem, but to then explain in words how and why your solution worked makes me understand the problem that much more.

Student \#2: This math class is very different from any math class I have taken before. I've been forced to think beyond a simple solution. I've been challenged in ways I've never been mathematically challenged before; however, I think this only betters my ability in mathematics. I think that this class will be very helpful for me in the future because I am thinking about teaching math. I will be able to use some of the problem solving strategies I have learned in my own classroom.

Student \#3: Before this class, my math teachers had me under the impression that it was always imperative to solve every problem their way, but in reality there are so many correct ways to solve most problems. In this class, it is not the student's responsibility to figure out the teacher's method, but it is the teacher's responsibility to figure out the student's method.

Student \#4: This math class has been very different from any of the others I have ever had in my educational career.... I did not leave the classroom wondering what I was doing or how to apply things outside of the class. I really appreciated the time I was given to make sense out of the problems. I really like that the professor took the time to relate our learning to younger students. My favorite section was Xmania. My eyes were really opened to what children have to deal with and I hope that I will remember my frustration from this section. It will help me understand my students' thinking and hopefully improve my teaching of our numeration system. Every topic was 
like this for me. I feel more confident about my understanding of mathematics. I feel that I learned how to understand math better than I ever did in my other classes. I feel that everyone should be required to take this course because it helps you develop critical thinking skills.

Student \#5: I didn't really think of this class as a true math class, but more of a class to teach me how to think. Typically, a math class at a high school or college level has you learn a lot of different formulas and this class took the formulas I knew from long ago and applied them in a totally different way. The class made me realize that math does not end with just learning formulas and doing problems, but that as you change the questions and apply what you have learned to new things, you learn more than you ever knew before.

Student \#6: Throughout this course I have found myself looking at mathematics in a totally different way. In the past, mathematics was always number crunching, memorization, and repetition. However, this class has shown me thinking processes of young children and it has opened up a side of mathematics that is very interesting. The process of the mind has made mathematics more interesting than I would have imagined while crunching out algorithms in the elementary classroom.

Student \#7: The math course has been one of the most interesting courses I have taken, not only in mathematics, but also in formal education. This class forced me to look into mathematics deeper than I was forced to in elementary and beyond. I was always taught the algorithms in school and allowed to slip past without truly understanding my answers. This math course differed greatly in that aspect. Although the math was not complex, it was difficult to see my solutions differently than I had previously. After taking this class, I will hope that I will NOT allow my students to pass mathematics without truly understanding.

Student \#8: This course has truly been unlike any other math course I have ever taken. With this course there was very little instruction from an instructor; it was almost all student discoveries. We had to determine our own steps for solving a problem, work together, trust our patterns and recording, then test each conjecture to see if they could be disproved. The tests, especially the first, then tested how well we could APPLY these strategies and the general mathematics knowledge. When we began this course, I felt (as I'm sure others did also) that this material would be easy; we had already learned these basics, even positive/negative numbers and bases in years prior. However, once we began to complete the questions, I realized it wasn't so easy. The group work and problem solving have given an in-depth look at each aspect of math we covered. I feel this deeper understanding will help me when I teach young students these topics.

Student \#9: The biggest thing I gained from this class is not to just fall back on formulas and rules, but to use logical thinking to find answers. With all the problems we did in and out of class, they helped strengthen this sense in me. In past math courses, I would just read the textbook, learn the examples, then practice until I was a little math machine. What I have learned from this class is that doing math by just going through the motions is inefficient and unproductive for students. They don't really understand why they are doing what they are doing and will never really grasp the concept and will forget it shortly after. I feel disappointed that it took me until I was a sophomore in college to really understand how our number system works. But I'm glad I understand it better now! I think this class will make me a better teacher in the future. Hopefully my students will enjoy math more than I did as a result of better teaching methods and instruction.

\section{References}

1. Burrill, G. (1998). President's report: Changes in your classroom: From the past to the present to the future. Journal of Research in Mathematics Education, Vol. 29.

2. Cangelosi, J.S. (2003), Teaching Mathematics in the Secondary and Middle School: An Interactive Approach, Third Edition. Merrill Prentice Hall, Pearson Education, Inc., Upper Saddle River, New Jersey.

3. Conference Board of the Mathematical Sciences (CBMS) (2001). The Mathematical Education of Teachers, Issues in Mathematics Education, Volume II. American Mathematical Society in cooperation with Mathematical Association of America. 
4. Fosnot, C.T. and Dolk, M (2002). Young Mathematicians at Work: Constructing Number Sense, Addition, and Subtraction. Heinemann, A division of Reed Elsevier, Inc, Portsmouth, New Hampshire.

5. Golafshani, N. (2002). Teachers' conceptions of mathematics and instructional practices, Philosophy of Mathematics Education Journal, 15. PoME Journal.

6. Hiebert, J., Carpenter, T.P., Fennema, E., Fuson, K, Wearne, D., Hanlie, M., Olivier, A., and Human, P. (1997). Making Sense: teaching and learning mathematics with understanding. Heinemann, A division of Reed Elsevier, Inc., Portsmouth, New Hampshire.

7. Joyce, B., Weil, M., and Calhoun, E. (2000). Models of Teaching, Sixth Edition. Allyn \& Bacon, A Pearson Education Company, Needham Heights, MA.

8. Kamii, C. and Dominick A. (1998). "The harmful effects of algorithms in grades 1-4." In The Teaching and Learning of Algorithms in School Mathematics, eds. L. Morrow and Kenney M. Reston, VA: National Council of Teachers of Mathematics.

9. Kubinova, M, (1999). The position of didactics of mathematics in the training of mathematics teachers. Philosophy of Mathematics Education Journal, 12. PoME Journal.

10. Masingila, J.O., Lester, F., Raymond, A. (2002). Mathematics for Elementary Teachers via Problem Solving, Student Activity Manual. Prentice Hall, Upper Saddle River, New Jersey.

11. Schifter, D., and Fosnot, C.T. (1993). Reconstructing mathematics education: Stories of teachers meeting the challenge of reform. New York: Teachers College Press.

12. Sellers, P. A., and Ahern, K.A. (2000). The TIMSS Report: Implications for teachers in a new millennium, International Journal of Educational Reform, Vol. 9, No. 4.

13. Steffe, L, and DeAmbrosio, B.S. (1995). Toward a working model of constructivist teaching: A reaction to Simon. Journal for Research in Mathematics Education, Vol. 26.

14. Wiersma, L, and Weinstein, G.L. (2001). Mathematical sophistocation and educational philosophies among novice mathematics teachers. Philosophy of Mathematics Education Journal, 14, PoME Journal.

15. Yackel, E, and Cobb, P. (1996). Sociomathematical norms, argumentation, and autonomy in mathematics. Journal for Research in Mathematics Education, Vol. 27. 
Notes 